\title{
LXVII. A search for the Heavier gases of the helium group in minerals
}

\section{C.F. Hogley A.R.C.Sc. B.Sc.}

To cite this article: C.F. Hogley A.R.C.Sc. B.Sc. (1909) LXVII. A search for the Heavier gases of the helium group in minerals, Philosophical Magazine Series 6, 18:106, 672-677, DOI: $10.1080 / 14786441008636735$

To link to this article: http://dx.doi.org/10.1080/14786441008636735

册 Published online: 21 Apr 2009.

Submit your article to this journal $\lceil\pi$

Џ Article views: 2

Q View related articles $₫$ 
of Prof. Richardson *, showing that the positive ionization can be greatly renewed in an old wire by the presence of oxygen, whereas the negative ionization is unaffected.

The author considers the gas theory, also suggested by Prof. Richardson $\dagger$, as promising as any in sight. In order to agree with his determinations of $\frac{e}{m}$ he suggests the possibility of the positive ions being $\mathrm{N}_{2}, \mathrm{CO}$, and $\mathrm{O}_{2}$.

There is no certain proof that these ions might not receive their charges from chemical action, which takes place when the metal is heated.

It may be possible by studying the products given off by a freshly heated body to determine which are the positive thermions. One method would be to separate the charged particles in sufficient quantity from the uncharged particles and to examine the spectrum. Another method would be to hunt for those spectral lines which are common to the products emitted by all the different thermionic radiators. The chief objection that may be urged against the last method lies in the fact that most of the metals, as shown by Delachanal $\ddagger$ give out many gases.

In conclusion $I$ again take this opportunity to express my highest regard for the encouragement and help received from Prof. O. W. Richardson.

Palmer Physical Laboratory, Princeton University.

LXVII. A Search for the Heavier Gases of the Helium Group in Minerals. By C. F. HogLey, A.R.C.Sc., B.Sc., Imperial College of Science $\$$.

\section{Part I. Argon in Malacone.}

$\bigcup^{P}$ to the present there has been considerable uncertainty as to the amount of argon contained in the mineral malacone. Several experimenters $\|$ have found that the quantity of argon is appreciable and in excess of the quantity of helium

* Phil. Trans. Series A, vol. 207, p. 1 (1906).

$\dagger$ Phil. Mag. ser. 6, Nov. 1908, p. 740 .

$\mp$ Science Abstracts, vol. xii. p. 249 (1909).

\$ Communicated by the Hon. R. J. Strutt, F.R.S.

II (i.) Von Antropoff, Zeitsch.f. Elektroch. 1908, vol. xiv.

(ii.) Kitchin \& Winterson, Chem. Soc. Trans. vol. 1xxxix. 1906, p. 1570. 
contained in the mineral, a result which Prof. Strutt has failed to confirm *. The experiments described in this paper were designed with the intention of obtaining some evidence on the subject which may be considered conclusive. The great source of error likely to occur in dealing with argon is by contamination of the gas with air, and the apparatus used was constructed to eliminate the possibility of this error. The liberation, purification, and examination of the gas took place in the same tube, from which air was entirely excluded. The apparatus shown in fig. 1 was exhausted until only a

Fig. 1.

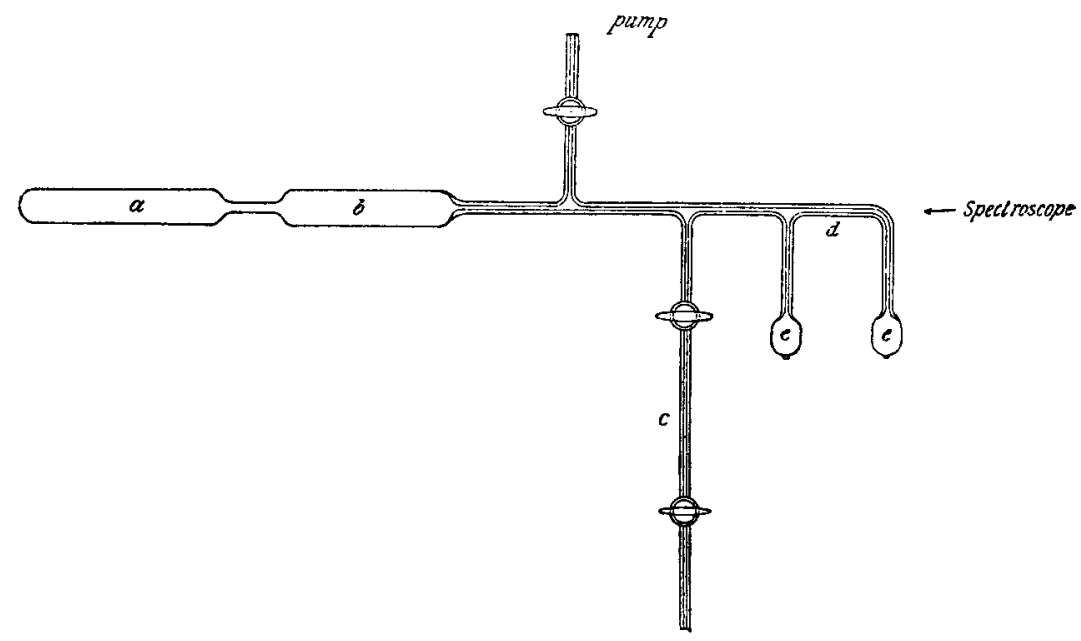

a. Hard glass tube containing mineral and copper oxide.

$b$. Phosplioric oxide to absorb moisture.

c. Inlet tube for nir. Volume between tars $0 \cdot 10$ c.c.

d. Vacuum-tube.

e-e. Bulbs containing liquid alloy of sodium and potassium.

very feeble discharge wonld pass through the racuum-tube, showing a faint spectrum of hydrogen. (The hydrogen was probably due to decomposition of the hydroxides of sodium and potassium, formed in sealing on the bulbs containing the electrodes, or from the glass itself.) The pump was closed when it seemed certain that nothing but hydrogen remained

* The Hon. R. J. Strutt, Proceedings Roy. Soc. A. vol.1xxx. 1ع08, note p. 593. 
in the apparatus, and the mineral was heated for about an hour. Any hydrogen was taken up by the copper oxide and the water was absorbed by the oxide of phosphorus. The remaining gases, excepting the inert elements, were absorbed by the sodium-potassium electrodes. In all the experiments, the residual gas showed the brilliant yellow helium glow in the vacuum-tube, and the spectroscope indicated little or no trace of argon, the gas being practically pure helium. (The bright orange argon line could be distinguished only faintly, whilst the red and blue lines were invisible in most cases.) To obtain some idea of the quantity of argon present with the helium, a cubic millimetre of argon was admitted into the apparatus containing the residual gas. This was done by admitting $0 \cdot 1$ c.c. of air by means of the side tube, shown in fig. 1, and absorbing all except argon by the sodium-potassium electrodes. It was found that this small quantity of argon gave a spectrum extending bevond the belium spectrum into the red, and also showing well defined lines in the violet, clearly proving that the quantity of argon present in the helium before admitting the air was much less than $1 \mathrm{cub} . \mathrm{mm}$. The quantity of mineral used for each experiment was 10 grams, and at the end of the experiment the helium was pumped off and measured. The volume was roughly $0 \cdot 10$ c.c. Thus the volume of argon was shown to be less than one per cent. of that of the helium obtained from malacone.

In one experiment the helium was liberated by decomposing the mineral with potassium bisulphate, and in the others by simple heating, but there was no appreciable difference in the results.

The results of the investigation show conclusively that argon is contained in this mineral in only minute quantities even in comparison with the helium. It is true that the gases are not entirely expelled by simple heating, but this would not account for the great discrepancies between the results of the various experimenters, and can scarcely affect the general conclusion.

\section{PART II. Krypton in Fergusonite.}

It is mentioned in a paper by Travers, Senter, and Jaquerod (Pbil. Trans. A. vol. 200. 1903, p. 174) that an appreciable quantity of krypton has been found in the mixed helium obtained from cleveite. If the presence of this gas were in any way connected with the radioactive properties of the mineral, there should be no reason to suppose that it would be present in one strongly active mineral rather than in another. The mineral used for this inrestigation was 
fergusonite, which gives off about 1 c.c. of helium per gram on heating, and is more easily obtained than cleveite.

The apparatus used (fig. 2) was exhausted whilst the charcoal bulb was continuously kept hot to expel all traces of air. It was then rinsed out with oxygen supplied by a side tube containing potassium permanganate, and again exhausted. The hard glass tube containing the mineral (ahout 140 grams) was heated in an ordinary combustionfurnace, and the gases conducted over suitable absorbents and

Fig. 2.

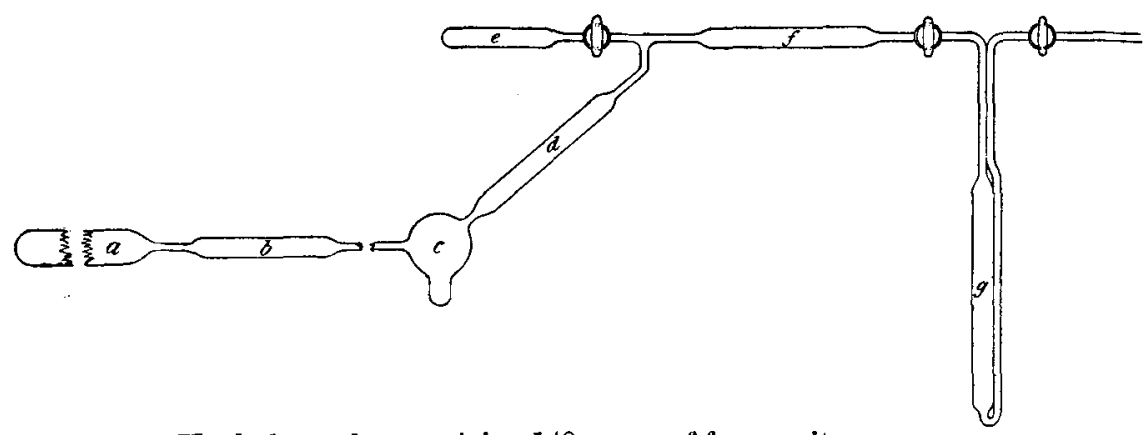

a. Hard gịss tube containing 140 grams of fergusonite.

$b$. Hot copper oxide for absorbing hydrogen.

c. Bulb for receiving condensed moisture and drainings from $d$.

d. Potassium hydroxide to absorb carbon dioxide.

$e$. Side tube for producing oxygen.

$f$. Phosphoric oxide to absorb last traces of water vapour.

g. Bulb containing charcoal for absorbing gases at low temperatures.

finally passed through charcoal cooled by liquid air. This absorbed all but the helium which was pumped away. When no more helium could be obtained, the heating was stopped and the charcoal heated to expel the absorbed gases, which were collected through the pump. The nitrogen was removed by sparking with excess of oxygen over hydrated potassium hydroxide for about half-an-hour. The excess of oxygen was removed by melted phosphorus and the residue introduced into the apparatus shown in fig. 3 (p. 676), where the last traces of all gases, except the inert gases, were removed by means of the sodium-potassium electrodes. Spectroscopic examination showed the presence of helium and argon in the tube. Before the presence of krypton could be investigated with certainty, the helium had to be removed. This was done by absorbing the argon, and heavier gases if present, with charcoal cooled by liquid air and pumping away the helium. After closing the pump and warming up the 
676 Heavier Gases of the Helinm Group in Minerals.

Fig. 3.

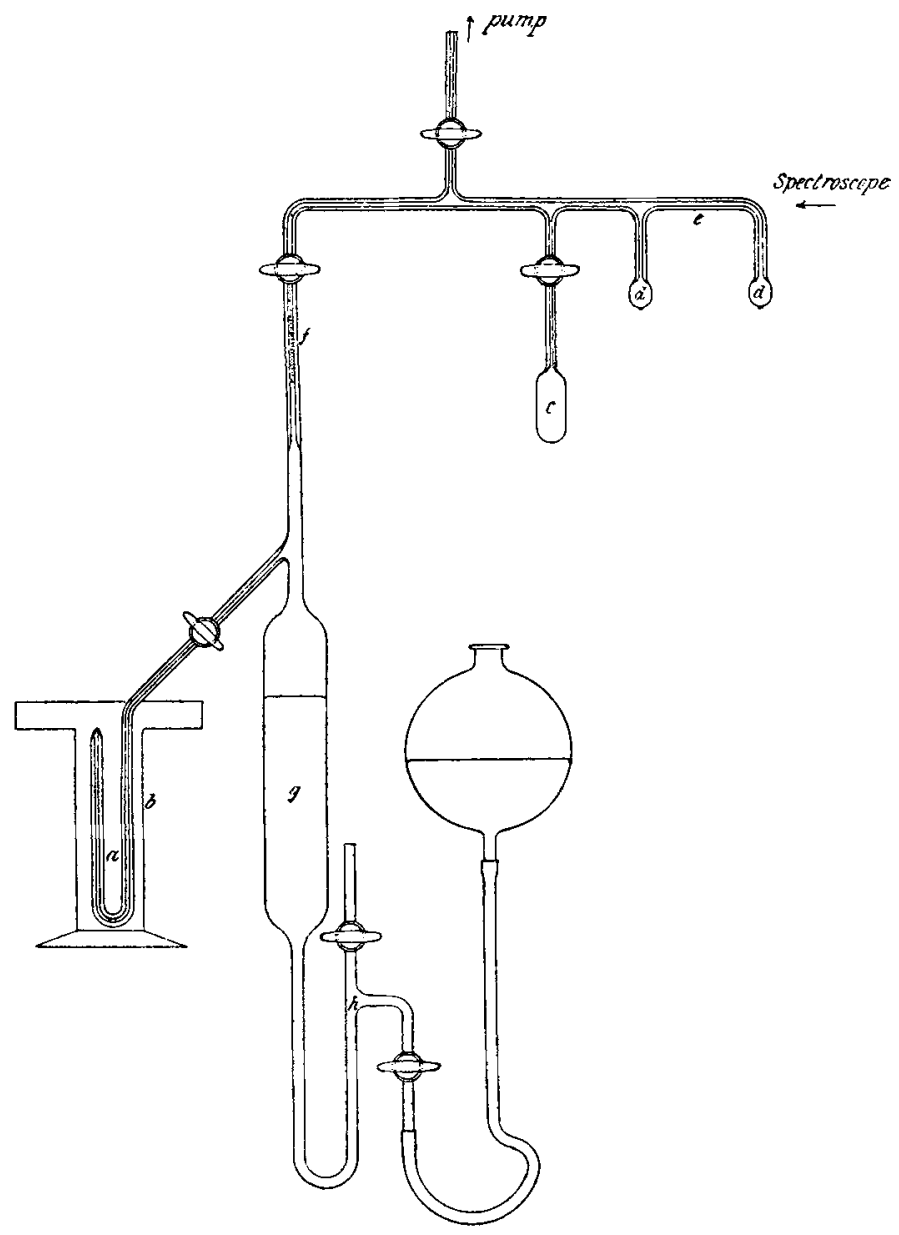

a. Tube for introducing gas into apparatus.

b. Mercury trough.

c. Charcoal bulb.

d-d. Sodium potassium electrodes.

e. Vacuum-tubes.

$f$. Graduated capillary for measuring gas,

$g$. Large bull into which gas is allowed to expand. The gas is h. Air trap. compressed into " $f$ " and measured. 
charcoal, the tube was found to contain argon only. No lines but those due to argon could be observed in the spectrum of the gas. The volume of the argon was measured by the McLeod gauge and found to be 3 cubic mm., a quantity which could be well accounted for by contamination with air in the course of transference from one vessel to another.

As krypton is very easily absorbed by charcoal in liquid air, it was thought advisable to make sure that none had remained in the large bulb used in the first part of the investigation. This bulb was maintained at a lemperature of $220^{\circ} \mathrm{C}$. for about 6 hours by means of an electric heater, and the expelled gas collected. The gas was practically all carbon dioxide, and after absorbing most of it with hydrated potassium hydroxide, the residue was introduced into the vacuum-tube and the discharge passed until all trace of carbon dioxide was removed. The spectram of the remaining gas was compared with that of krypton, but no agreement was found in any of the lines.

The amount of helium given off by the mineral was in round numbers 100 e.cs. Had there been present with it $\frac{1}{10}$ of a c.c. of krypton, the spectrum of the latter would have been conspicuous when the residue was examined: hence the experiment points to the conclusion that krypton, if present at all, which is indeed doubtful, must amount to less than one part in a million of the helium content. As opportunity affords it is intended to carry on the investigation with respect to other strongly radioactive minerals, as it is not to be expected that definite results can be drawn from the behaviour of one mineral.

In conclusion I beg to express my thanks to Professor Strutt for suggesting this research and for his valuable advice during its procedure.

LXVIII. Radioactive Minerals in Common Rocks. By J. W. Waters, B.Sc., Imperial College of Science, South Kensington *.

T $\mathrm{T}$ has been shown by Rutherford and Strutt that a know1 ledge of the amount of uranium and also the amount of helium contained in a rock or mineral enables us to form a minimum estimate of its age. In making accurate measurements of these quantities it is much more convenient to experiment upon substances comparatively rich in radioactive constituents. Prof. Strutt has found that the phosphatic nodules and phosphatized bones which occur in

* Communicated by the Hon. R. J. Strutt, F.R.S. 